\title{
A COMPARATIVE CLINICAL STUDY OF DIFFERENT PROSTHESES USED IN OSSICULOPLASTY
}

\author{
S. Muneeruddin Ahmed ${ }^{1}$, A. Siva Kumar ${ }^{2}$ \\ 1 Professor, Department of ENT, Kannur Medical College, Anjarakandy, Kannur. \\ 2 Professor, Department of ENT, Kannur Medical College, Anjarakandy, Kannur.
}

ABSTRACT

\section{BACKGROUND}

Ossiculoplasty is done using various kinds of prosthesis to improve hearing in CSOM patients. The type of prostheses may be an allograft, homograft or synthetic materials of Teflon, titanium, gold and steel. The results vary depending upon the Ossicular damage, surgeon's technique and selection of the type of the prosthesis used. The present study attempted to compare the final results of Ossiculoplasty using different prostheses.

The aim of this study is to compare the final healing and hearing results in patients where different types of prostheses are used.

\section{MATERIALS AND METHODS}

Randomly selected 72 patients were equally divided into 4 groups depending on the type of prosthesis used; group A received Patient's incus, group B Homograft septal cartilage, group C Teflon piston and group D titanium prosthesis. Canal wall up and down (CWU \& CWD) Mastoidectomy followed by Tympanoplasty was done. Partial and Total Ossicular replacements were done (PORP \& TORP). Pre-operative and post-operative hearing results were compared among all the groups.

Study Design- A randomised comparative study with retrospective and prospective clinical data.

\section{RESULTS}

72 patients were aged between 18 and 65 years and mean age was $29.5 \pm 2.4$ years. CSOM (Atticoantral type) accounted for 45 (62.5\%), CSOM (Tubotympanic) $16(22.22 \%)$ and trauma 11 (15.27\%) patients. Chi-Square Calculator for goodness of Fit was used to calculate the Chi-square value and it was 1.722 and $p$ value was 0.632 (The result not significant at $p=<0.05$ ). The graft uptake was good in $95.83 \%$. Prostheses extrusion was observed in $4.16 \%$ of the patients.

\section{CONCLUSION}

There was no statistical significance in the auditory gain observed following Ossiculoplasty using different prostheses in the patients of present study. The study supports several other studies in the literature which are conducted with similar clinical conditions.

\section{KEYWORDS}

CSOM, Tympanoplasty, Ossiculoplasty, Ossicular Prosthesis, Air Bone Gap, Auditory Gain.

HOW TO CITE THIS ARTICLE: Ahmed SM, Kumar SA. A comparative clinical study of different prostheses used in ossiculoplasty. J. Evolution Med. Dent. Sci. 2017;6(23):1894-1897, DOI: 10.14260/Jemds/2017/416

\begin{abstract}
BACKGROUND
Repair of damaged Ossicular chain and restoration of continuity in Ossicular chain to improve hearing in $\mathrm{CSOM}$ /trauma is a challenging and delicate task an Otological surgeon faces. ${ }^{1}$ Nearly $60 \%$ of patients with chronic otitis media are reported to have Ossicular involvement; therefore the need for Ossiculoplasty is compulsory. ${ }^{2}$ The types of prosthesis used nowadays are many like alloplastic, autograft, and homograft prostheses giving variable success; whereas an ideal Ossicular prosthesis should be easily prepared, less time consuming, manageable, biocompatible and stable over time. ${ }^{3,4}$ Sculpted autologous or homologous incus interposition provides hearing success comparable with current allograft prosthesis studies, has a very low
\end{abstract}

Financial or Other, Competing Interest: None.

Submission 09-02-2017, Peer Review 04-03-2017,

Acceptance 13-03-2017, Published 20-03-2017.

Corresponding Author:

Dr. S. Muneeruddin Ahmed,

Professor,

Department of ENT,

Kannur Medical College, Anjarakandy,

Kannur.

E-mail: ahmedmunirent@gmail.com

DOI: $10.14260 /$ jemds $/ 2017 / 416$

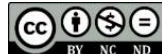

extrusion rate, and remains stable over time. ${ }^{5}$ Autologous incus has no risk of transmission of disease and no extra cost involved. ${ }^{6}$ Titanium (Ti) is an excellent biocompatible material and suitable for Ossicular reconstruction because of low ferromagneticity. ${ }^{7-10}$ Titanium being strong and light can be moulded into thin prosthesis yet a rigid and good sound conductor. ${ }^{9}$ In this context the present study is conducted to compare the 4 types of prostheses regularly used in our institute to analyse the long term healing and results of hearing improvement in patients receiving the prostheses.

\section{MATERIALS AND METHODS}

The study period is between Jan. 2012 and Jan. 2017. Retrospectively, 54 case records of patients receiving middle ear prosthesis were obtained from medical records section of the Hospital to scrutinise and analyse the observations made by previous surgeons while performing the Ossiculoplasty (Jan. 2012 to Dec. 2015). Prospectively between Dec. 2015 to Jan. 2017, 18 patients were randomly selected for insertion of prosthesis after undertaking surgical profile and audiological evaluation. Ethical clearance certificate was obtained from the Institute. Necessary proforma filled and consent was obtained from the patients. Audiological evaluation findings and per-operative findings of the patients were tabulated and compared before and after Ossiculoplasty using standard 
statistical methods. Patients were randomised using online Research Randomiser, 4 sets of 18 unique numbers per set; Range: from 1-72- sorted from least to greatest number.

\section{Inclusion Criteria}

1. Patients aged above 18 years and below 65 years were included. 2. Patients with CSOM and trauma were included. 3. Only patients being operated for first time were included.

\section{Exclusion Criteria}

1. Patients aged below 18 years and above 65 years were excluded. 2. Post-operative failed cases were excluded from the study.

Overall 72 patients were divided equally in to 4 groups. Group A patients received Patient's own incus (Re-shaped), group B Homograft septal cartilage (Harvested and preserved in Absolute alcohol; necessary viral screening/or VDRL screening of the host were done earlier), group C Teflon piston and group $\mathrm{D}$ titanium prosthesis. All the patients were subjected to standard audiological evaluation of Air, Bone conductions done and wherever necessary masking (Plateau method) was used. CSOM patients of all groups were subjected to Type $2 \mathrm{~b}$ and Type 3 type of Tympanoplasty and underlay graft was done with earlier Mastoidectomy either Canal Wall Up (CWU) or Canal Wall Down (CWD). PostTrauma patients underwent $2 \mathrm{~b}$ type of Tympanoplasty.

\section{Protocol for Evaluation}

All the patients were followed up to 18 months by monthly followup for initial 3 months followed by 5 monthly intervals. The patients were evaluated for graft healing, Pure tone audiometry, a-b gap closure and speech audiometry gain in hearing were taken into consideration for the success of the procedures. The data was recorded in tabulation and analysed using standard statistical methods available online where in "Chi-Square Calculator for goodness of Fit" was used to calculate the $\mathrm{Chi}^{\wedge}$ value and reported.

\section{RESULTS}

Among the 72 patients, $47(65.27 \%)$ were male and 25 $(34.72 \%)$ were female with a male to female ratio of $1: 1.88$. The patients were in the age groups of 18 to 65 years with a mean age of $29.5 \pm 2.4$ years. Patients belonging to the age group of 18 to 33 were 45 (62.5\%), followed by the age group of 34 to 49 years (26.38\%). Among the indications for Ossiculoplasty, CSOM Atticoantral type accounted for 45 (62.5\%), CSOM Tubotympanic 16 (22.22\%) and trauma 11 (15.27\%) patients (Table 1$)$.

\begin{tabular}{|c|c|c|c|c|}
\hline Observation & $\begin{array}{c}\text { Group } \\
\text { A-18 }\end{array}$ & $\begin{array}{r}\text { Group } \\
\text { B-18 }\end{array}$ & $\begin{array}{c}\text { Group } \\
\text { C-18 }\end{array}$ & $\begin{array}{r}\text { Group } \\
\text { D-18 }\end{array}$ \\
\hline Male- 47 & 12 & 14 & 11 & 10 \\
\hline Female- 25 & 06 & 04 & 07 & 08 \\
\hline 18 to 33 yrs. & 11 & 09 & 13 & 12 \\
\hline 34 to 49 yrs. & 05 & 06 & 03 & 05 \\
\hline 50 to 65 yrs. & 02 & 03 & 02 & 01 \\
\hline Atticoantral-45 & 11 & 10 & 12 & 12 \\
\hline \begin{tabular}{|c|c|} 
CSOM & Tubotympanic- \\
& 16 \\
\end{tabular} & 05 & 04 & 03 & 04 \\
\hline Trauma-11 & 02 & 04 & 03 & 02 \\
\hline
\end{tabular}

Audiological evaluation of patients pre-operatively showed a-b Gap of 15 to $25 \mathrm{~dB}$ in 10 patients (13.88\%), 26 to $35 \mathrm{~dB}$ in 45(62.5\%) and above $36 \mathrm{~dB}$ in 17 (23.61\%) patients and were found to be equally distributed among all the 4 groups and had no statistical significance (Table 2). Similarly, the SRT (Speech reception threshold) was between 85 to $95 \%$ in all the patients of 4 groups without any significance statistically. Patients showing only absence of Incus were 49 $(68.05 \%)$, absence of both incus and stapes was seen in 15 (20.83\%) patients and absence of all ossicles was found in 11 $(15.27 \%)$ patients. Speech reception thresholds were ranging between 85 to $95 \%$ in all the groups of patients (Table 2).

\begin{tabular}{|c|c|c|c|c|c|}
\hline \multicolumn{2}{|c|}{ Observation } & $\begin{array}{c}\text { Group } \\
\text { A-18 }\end{array}$ & \begin{tabular}{|c|} 
Group \\
B-18
\end{tabular} & $\begin{array}{c}\text { Group } \\
\text { C-18 }\end{array}$ & $\begin{array}{c}\text { Group } \\
\text { D-18 }\end{array}$ \\
\hline \multicolumn{2}{|r|}{$\mathrm{M}+, \mathrm{I}-, \mathrm{S}+$} & 12 & 13 & 12 & 10 \\
\hline \multicolumn{2}{|r|}{$\mathrm{M}+, \mathrm{I}-, \mathrm{S}-$} & 04 & 03 & 04 & 04 \\
\hline \multicolumn{2}{|r|}{ M-, I-, S- } & 02 & 02 & 02 & 04 \\
\hline \multirow{3}{*}{$\begin{array}{l}\text { a-b } \\
\text { Gap }\end{array}$} & $15-25 \mathrm{~dB}-10$ & 03 & 03 & 02 & 02 \\
\hline & $26-35 \mathrm{~dB}-45$ & 11 & 09 & 13 & 12 \\
\hline & $>36 \mathrm{~dB}-17$ & 04 & 06 & 03 & 04 \\
\hline \multicolumn{2}{|c|}{ SRT } & $85-95 \%$ & $85-95 \%$ & $85-95 \%$ & $85-95 \%$ \\
\hline \multicolumn{6}{|c|}{$\begin{array}{l}\text { Table 2. Showing the a-b gap and Ossicular Status of } \\
\text { Patients } n=72\end{array}$} \\
\hline
\end{tabular}

During surgery depending upon the Ossicular damage the types of Ossicular replacements used were observed to be (Partial Ossicular Replacement Prosthesis) PORP in 40 patients (55.55\%) and (Total Ossicular Replacement Prosthesis) TORP in 32 patients (44.44\%). The biogenic PORPs used were 25/40 (62.5\%) and synthetic PORPs were $15 / 40$ (37.5\%). The biogenic TORPs were 04/32 (12.5\%) and synthetic TORPs were 28/32 (87.5\%), (Table3).

\begin{tabular}{|c|c|c|c|c|}
\hline Observation & $\begin{array}{c}\text { Group } \\
\text { A-18 }\end{array}$ & $\begin{array}{c}\text { Group } \\
\text { B-18 }\end{array}$ & $\begin{array}{c}\text { Group } \\
\text { C-18 }\end{array}$ & $\begin{array}{c}\text { Group } \\
\text { D-18 }\end{array}$ \\
\hline $\begin{array}{c}\text { PORP used-40 } \\
\text { (55.55\%) }\end{array}$ & 13 & 12 & 08 & 07 \\
\hline $\begin{array}{c}\text { TORP used-32 } \\
(44.44 \%)\end{array}$ & 05 & 06 & 10 & 11 \\
\hline
\end{tabular}

Table 3. Showing the TORP and PORP used in the Study $(n=72)$

Gain in hearing levels measured in terms of closure of air bone gap after surgery evaluated at the end of 1 year in all the patients put together was found to be in 63 out of 72 patients (87.50\%). There were 9 patients in whom the a-b gap gain was less than $10 \mathrm{~dB}(12.5 \%)$. The air-bone gap closure ranged from less than $10 \mathrm{~dB}$ to $25 \mathrm{~dB}$. Closure of air-bone gap of less than $10 \mathrm{~dB}$ to $10 \mathrm{~dB}$ was found in $10 / 63$ (15.87\%) of the patients, closure between 15 to $20 \mathrm{~dB}$ was observed in $38 / 72$ $61.90 \%$ ) and between 20 and $25 \mathrm{~dB}$ was observed in 15 (26.98\%). Group wise comparison of hearing gain in terms of air-bone gap in group was 17/18 (94.44\%), in group B 14 $(97.77 \%)$, in group C $13(72.22 \%)$ and in group D 16 (88.88\%). Chi-Square Calculator for $5 \times 5$ contingency table was used to calculate the $\mathrm{p}$ value and the chi square was 0.642 and $p$ value was 0.995 (the result not significant at $p=<$ 0.05), (Table 4). Hence, it was concluded that the material and type of prosthesis used in Ossiculoplasty was not significant in achieving auditory gain in patients. Speech reception thresholds improved to 90 to $95 \%$ in all the patients. The graft uptake was good in $95.83 \%$. Prostheses extrusion was observed in $4.16 \%$ of the patients. 


\begin{tabular}{|c|c|c|c|c|c|c|}
\hline \multicolumn{2}{|c|}{ Observation } & Group A-18 & Group B-18 & Group C-18 & Group D-18 & \\
\hline \multirow{3}{*}{$\begin{array}{c}\text { Closure of a-b Gap-63 } \\
(87.5 \%)\end{array}$} & $<10 \mathrm{~dB}-10-(15.87 \%)$ & 03 & 03 & 02 & 02 & \\
\hline & $15-20 \mathrm{~dB}-38-(60.31 \%)$ & 10 & 08 & 10 & 10 & \\
\hline & $20-25 \mathrm{~dB}-15(23.80 \%)$ & 04 & 03 & 04 & 04 & \\
\hline \multicolumn{2}{|c|}{ Total-\% 63/72 (87.5\%) } & $17-94.44 \%$ & $14-72.22 \%$ & $16-88.88 \%$ & $16-88.88 \%$ & $\mathrm{P}=0.995$ \\
\hline \multicolumn{2}{|c|}{ SRT } & $90-95 \%$ & $90-95 \%$ & $90-95 \%$ & $90-95 \%$ & \\
\hline \multicolumn{2}{|c|}{ Graft uptake - $69(95.83 \%)$} & 17 & 17 & 17 & 18 & \\
\hline Prostheses extr & ion- $03(4.16 \%)$ & 00 & 00 & 02 & 01 & \\
\hline & ble 4. Showing the Posto & rative Result & of the Study (n & $=72)$ & & \\
\hline
\end{tabular}

\section{DISCUSSION}

Over the recent years there is lot of improvement in the hearing results in patients following Tympanoplasty procedures due to advancement of surgical techniques, access to surgical videos for the beginners. But there are variable success reports in the literature regarding auditory gain in patients; may be due to ununiformed selection of patients and middle ear status reporting. Whatever the prosthesis used should connect with its ends to the soft tissue or bone snugly at optimal angle and remain suspended in the air to conduct sound effectively. Ossicular implants are subject to extrusion, infection and resorption from changing pressures of middle ear and tubal dysfunction; in case of homografts, subject to immune mediated rejection. ${ }^{11} 72$ patients of this study belonged to the age group of 18 to 65 with a mean age of $29.5 \pm 2.4$. Males are more than females with an $\mathrm{M}$ : $\mathrm{F}$ of $1: 1.88$. Most of the studies confirm that autologous prostheses provide excellent results whereas synthetic materials give much variable results; titanium PORPs give equal or much better results than autologous grafts 12,13 while Hydroxyapatite PORPs give less favourable results.14,15,16 Titanium has been shown to be a highly biocompatible material and reliable implant in such reconstruction. It is an effective and easy material in handling which led to the development of new and versatile designs. ${ }^{11,17,18}$ Badr Eldin Mostafa quoted as hearing results reaching as high as $81 \%$ in their study. ${ }^{16}$ Similar results were reported with titanium implants. ${ }^{14-17}$ In the present study, the auditory gain in terms of closure of air-bone gap was $87.5 \%$. The results of Ossiculoplasty are to be interpreted in the light of anatomical, pathophysiologic and technical factors which can affect the functional outcome.17-19 These include revisions versus one stage surgeries.12,18,20 The presence or absence of cholesteatoma was considered to contribute to the results of Ossiculoplasty. In the present study, the CSOM patients with Cholesteatoma were 45 (62.5\%) and all these surgeries were done as a single stage operation. Whereas in the study by Badr Eldin Mostafaet al, ${ }^{16}$ Cholesteatoma cases were eliminated as all the reconstruction were done as a planned second procedure in them, and were eliminated in the presence of Cholesteatoma as they were cause of lower results. Other authors did not find any difference between reconstruction with or without Cholesteatoma surgery during the same procedure as was done in this study. The type of Mastoidectomy whether CWU or CWD also blamed for the Ossiculoplasty results, ${ }^{21}$ but in the present study the results of all types of Mastoidectomy were combined to find the final results of Ossiculoplasty. The net hearing gain results also depend upon the Ossicular destruction found at the time of surgery; however, use of PORP (Partial Ossicular Replacement Prosthesis) would not give better results over TORP (Total Ossicular Replacement Prosthesis); De Corso E et al in their study could not observe lower hearing gain results using TORP in CWD Mastoidectomy. ${ }^{22}$ PORP was used in $40 / 72(55.55 \%)$ and TORP in 32/72 (44.44\%) patients in this study. However, many authors opine that factors like preservation of external auditory canal, presence of stapes, the combination of CWD with TORP and CWU with TORP would significantly influence the hearing gain in patients. The combination of CWD and TORP gave significant inferior hearing thresholds as compared to TORP/CWU and PORP/CWD combinations. ${ }^{12,23,24}$ In the present study, wherein PORP and TORP are used in almost equally the net gain in hearing was in $87.5 \%$ of the patients. The graft uptake was good in $95.83 \%$ of the patients and prosthesis extrusion was found in $4.16 \%$ of the patients.

\section{CONCLUSION}

There was no statistical significance in the auditory gain observed following Ossiculoplasty using different prostheses in the patients of present study. The study supports several other studies in the literature which are conducted with similar clinical conditions. The selection of patients and the fixed protocol used in the surgical management of CSOM is more significant. A prospective study with a longer period of followup is necessary to achieve a more definitive comparison between different prostheses.

\section{REFERENCES}

[1] Maassen MM, Lowenheim H, Pfister M, et al. Surgicalhandling properties of the titanium prosthesis in ossiculoplasty. Ear Nose Throat J 2005;84(3):142-4.

[2] Chole RA. Ossiculoplasty with presculpted banked cartilage. Otolaryngol Clin North Am 1994;27(4):71726.

[3] Hales NW, Shakir FA, Saunders JE. Titanium middle ear prostheses in staged ossiculoplasty: does mass really matter? Am J Otolaryngol 2007;28(3):164-7.

[4] Artuso A, di Nardo W, De Corso E, et al. Canal wall down tympanoplasty surgery with or without ossiculoplasty in cholesteatoma: hearing results. Acta Otorhinolaryngol Ital. 2004;24(1):2-7.

[5] O'Reilly RC, Cass SP, Hirsch BE, et al. Ossiculoplasty using incus interposition: hearing results and analysis of the middle ear risk index. Otol Neurotol 2005;26(5):853-8.

[6] Bihani A, Dhabolkar J. Use of incus as an interposition graft in ossiculoplasty for type IIb tympanoplasty. Int J Clin Trials 2015;2(2):43-6.

[7] Martin AD, Harner SG. Ossicular reconstruction with titanium prosthesis. Laryngoscope 2004;114(1):61-4.

[8] Gardner EK, Jackson CG, Kaylie DM. Results with titanium ossicular reconstruction prostheses. Laryngoscope 2004;114(1):65-70. 
[9] Menendez-Colino LM, Bernal-Sprekelsen M, Alobid I, et al. Preliminary functional results of tympanoplasty with titanium prostheses. Otolaryngol Head Neck Surg 2004;131(5):747-9.

[10] Committee on hearing and equilibrium. Guidelines for the evaluation of results of treatment of a conductive hearing loss. American academy of otolaryngologyhead and neck surgery foundation, Inc. Otolaryngol Head Neck Surg 1995;113(3)186-7.

[11] Chavan SS, Jain PV, Vedi JN, et al. Ossiculoplasty: a prospective study of 80 cases. Iran J Otorhinolaryngol 2014;26(76):143-50.

[12] Neudert M, Zahnert T, Lasurashvili N, et al. Partial ossicular reconstruction: comparison of three different prostheses in clinical and experimental studies. Otol Neurotol 2009;30(3):332-8.

[13] Zhang LC, Zhang TY, Dai PD, et al. Titanium versus non-titanium prostheses in ossiculoplasty: a metaanalysis. Acta Otolaryngol 2011;131(7):708-15.

[14] Truy E, Naiman AN, Pavillon C, et al. Hydroxyapatite versus titanium ossiculoplasty. Otol Neurotol 2007;28(4):492-8.

[15] Gelfand YM, Chang CY. Ossicular chain reconstruction using titanium versus hydroxyapatite implants. Otolaryngol Head Neck Surg 2011;144(6):954-8.

[16] Mostafa BE, Fiky LE, Hassan O. Functional results in ossiculoplasty with different titanium prostheses. Egyptian Journal of Ear, Nose, Throat and Allied Sciences 2013;14(2):79-84.
[17] Vassbotn FS, Møller P, Silvola J. Short-term results using Kurz titanium ossicular implants. Eur Arch Otolaryngol 2007;264(1):21-5.

[18] Roth JA, Pandit SR, Soma M, et al. Ossicular chain reconstruction with a titanium prosthesis. J Laryngol Otol 2009;123(10):1082-6.

[19] Martin TP, Weller MD, Kim DS, et al. Results of primary ossiculoplasty in ears with an intact stapes superstructure and malleus handle: inflammation in the middle ear at the time of surgery does not affect hearing outcomes. Clin Otolaryngol 2009;34(3):21824.

[20] Dornhoffer JL, Gardner E. Prognostic factors in ossiculoplasty: a statistical staging system. Otol Neurotol 2001;22(3):299-304.

[21] Iniguez-Cuadra R, Alobid I, Bores-Domenech A, et al. Type III tympanoplasty with titanium total ossicular replacement prosthesis: anatomic and functional results. Otol Neurotol 2010;31(3):409-14.

[22] De Corso E, Marchese MR, Sergi B, et al. Role of ossiculoplasty in canal wall down tympanoplasty for middle-ear cholesteatoma: hearing results. J Laryngol Otol 2007;121(4):324-8.

[23] Nguyen DQ, Lavieille JP, Schmerber S. Failure rate and revision surgery in ossiculoplasty with Kurz titanium prosthesis. Rev Laryngol Otol Rhinol (Bord) 2004;125(3):157-62.

[24] Ho SY, Battista RA, Wiet RJ. Early results with titanium ossicular implants. Otol Neurotol 2003;24(2):149-52. 